\title{
Evolution of Drought-Flood Abrupt Alternation and Its Impacts on Surface Water Quality from 2020 to 2050 in the Luanhe River Basin
}

\author{
Wuxia Bi ${ }^{1,2} \mathbb{1}$, Baisha Weng ${ }^{1, *}$, Zhe Yuan ${ }^{1,3}$, Yuheng Yang ${ }^{1}$, Ting $X u^{1} \oplus$, Dengming Yan ${ }^{1,4}$ and \\ Jun Ma ${ }^{1,5}$ \\ 1 State Key Laboratory of Simulation and Regulation of Water Cycle in River Basin, \\ China Institute of Water Resources and Hydropower Research, Beijing 100038, China; \\ biwuxia_1992@163.com (W.B.); yuanzhe_0116@126.com (Z.Y.); sduyyh@126.com (Y.Y.); \\ xuting900515@163.com (T.X.); 18519500795@163.com (D.Y.); 18303011501@163.com (J.M.) \\ 2 College of Hydrology and Water Resources, Hohai University, Nanjing 210098, China \\ 3 Changjiang River Scientific Research Institute, Wuhan 430010, China \\ 4 College of Environmental Science and Engineering, Donghua University, Shanghai 201620, China \\ 5 School of Water Conservancy and Hydroelectric Power, Hebei University of Engineering, \\ Handan 056021, China \\ * Correspondence: wengbs@iwhr.com; Tel.: +86-152-1036-3283
}

Received: 17 December 2018; Accepted: 22 February 2019; Published: 26 February 2019 updates

\begin{abstract}
It has become a hot issue to study extreme climate change and its impacts on water quality. In this context, this study explored the evolution characteristics of drought-flood abrupt alternation (DFAA) and its impacts on total nitrogen (TN) and total phosphorous (TP) pollution, from 2020 to 2050, in the Luanhe river basin (LRB), based on the predicted meteorological data of the representative concentration pathways (RCPs) climate scenarios and simulated surface water quality data of the Soil and Water Assessment Tool (SWAT) model. The results show that DFAA occurred more frequently in summer, with an increasing trend from northwest to southeast of the LRB, basically concentrated in the downstream plain area, and the irrigation area. Meanwhile, most of the DFAA events were in light level. The incidence of TN pollution was much larger than the incidence of TP pollution and simultaneous occurrence of TN and TP pollution. The TN pollution was more serious than TP pollution in the basin. When DFAA occurred, TN pollution almost occurred simultaneously. Also, when TP pollution occurred, the TN pollution occurred simultaneously. These results could provide some references for the effects and adaptation-strategies study of extreme climate change and its influence on surface water quality.
\end{abstract}

Keywords: drought-flood abrupt alternation; tempo-spatial evolution; surface water quality; model simulations; Luanhe River Basin

\section{Introduction}

The term "drought-flood abrupt alternation (DFAA)" was first proposed in 2006 and refers to persistent drought for certain continuous days in one basin or region, followed by sudden heavy precipitation, resulting in steep river water and farmland waterlogging [1]. The DFAA event is an extreme hydrological event in which drought and flood occur alternately in the short term. Affected by global climate change, the extreme non-uniformity of precipitation on a time scale is more prominent in a basin or region, and the frequency and intensity of DFAA events have also increased significantly, such as in south-west Australia, and in the middle and lower reaches of the Yantze River in China. [2,3]. 
Therefore, DFAA has become one of the hot issues in relevant fields, such as meteorology, hydrology, and agriculture.

Current research of DFAA, includes mechanism analysis, evolution characteristics and disaster damage of DFAA events. The mechanism analysis shows that DFAA events are closely related to atmospheric circulation, monsoon and subtropical highs, and topographical conditions of the basin [4-6]. Hastenrath et al. [7] studied the atmospheric circulation mechanisms of the drought and flood anomalies in the boreal autumn "short rains" season in eastern equatorial Africa from 2005 to 2008. Wu et al. [8] and Feng et al. [9] simulated the drought and flood events in the middle and lower reaches of the Yangtze River in late spring and early summer of 2011, based on the ERA-40 re-analysis data and the NOAA-Hysplit model, indicating that the severe droughts were affected by the Ryanna event and the abnormal cold sea temperature control in the equatorial Indian Ocean. With the weakening of the cold sea temperature in the equatorial central and eastern Pacific and the Indian Ocean, abnormal precipitation occurred, which was the main cause of the drought and flood events. Yang et al. [10] also analyzed the characteristics of droughts and floods in the middle and lower reaches of the Yangtze River in 2011. In addition, some other researchers, such as Shen et al. [11], Li et al. [12], and Ma et al. [13], used statistical methods to explore the correlations between DFAA events and large-scale circulation, sea temperature anomalies, and low-frequency circulations. The central-eastern region or basin of China is prone to recurrence of DFAA, and presents different evolution characteristics [14-16]. Yan et al. [17] systematically analyzed the evolution characteristics of drought and flood events, based on the daily precipitation data of 171 meteorological stations in Huang-Huai-Hai River Basin from 1961 to 2011. The results show that, as the drought frequency increases, some areas of the basin become more vulnerable to extreme precipitation processes. Research on disaster damage, caused by droughts and floods, has focused on the study of crop physiological characteristics and regional ecological environment [18-21]. The former relevant studies mainly focus on the meteorological significance of DFAA, while there is relatively scant research on the characteristics analysis, based on the meteorological-hydrological coupling system and the impacts of DFAA on the ecological environment.

Several researchers have carried out related research work on the effects of single drought or single flood events on the migration and transformation of watershed pollutants, as well as the surface water quality [22-26]. However, a study looking at the impact of DFAA events on surface water quality is still in its infancy [26,27]. The eutrophication of water bodies has become a global concern. Nitrogen and phosphorus are two of the most important factors affecting the eutrophication of surface water bodies [28,29], especially in freshwater bodies [30]. Therefore, it is of great significance to study the DFAA impacts on surface water quality, especially the pollution of nitrogen and phosphorus.

According to the "2016 State of the Environment," the water pollution in the Haihe River Basin (including the Luanhe River Basin (LRB)) is still serious, although the surface water quality has improved compared to previous years [31]. According to the Environmental Quality Standards for Surface Water (GB3838-2002), there are about five classes of water quality. The water quality in Class IV is applicable to the general industrial protection areas and recreational areas with indirect contact to humans, while water quality below Class IV does not have much use. The monitoring results showed that, polluted rivers with water quality in Class IV and below accounted for $43.2 \%$ of all evaluated rivers in the last ten years [32]. The main pollution indicators of surface water in the LRB were ammonia nitrogen, total nitrogen (TN), and total phosphorus (TP) [33]. As DFAA could lead to sudden water pollution incidents in the LRB, it is of great importance to study the evolution characteristics of DFAA and its impact on surface water quality in the LRB.

The main objectives of our study were to: (i) establish a systematic evaluation standard of DFAA in the LRB; (ii) predict the spatial and temporal evolution characteristics of DFAA from 2020 to 2050 in the LRB; and (iii) investigate the impacts of DFAA events on TN and TP pollution. Under three Representative Concentration Pathways (RCPs) climate scenarios, future climate change was predicted. And the evolution characteristics of total nitrogen (TN) and total phosphorus (TP) load in the LRB 
were investigated, which were based on the calibration and validation of the hydrological calibration process and water quality of the SWAT model. The research process contains four parts (Figure 1): (i) selection of a future climate scenario based on RCPs; (ii) analysis of the tempo-spatial changes of DFAA in the LRB by a set of criteria proposed; (iii) simulation of TN and TP load with calibration and validation of the SWAT model; and (iv) evaluation of the impacts of DFAA on surface water quality by calculating the incidence of TN and TP pollution. The broad implication of the present research is to better understand the future evolution trends of DFAA in the LRB. The impact analysis of DFAA on surface water quality can guide the adaptation strategies for the changed environment. The evolution mechanism of DFAA and the corresponding surface water quality changes from 2020 to 2050 would provide references for the future planning of disaster preventions, agricultural development, and so on.
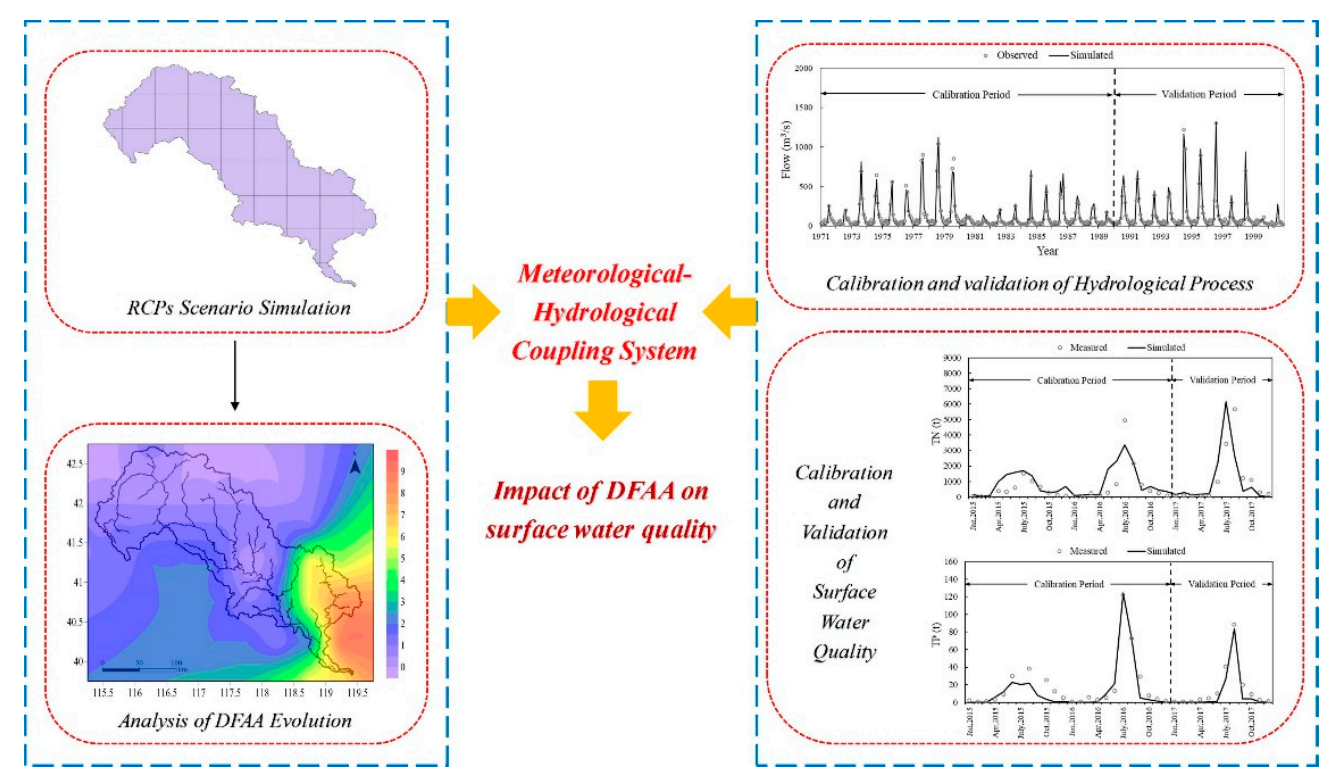

Figure 1. The framework of this study.

\section{Materials and Methods}

\subsection{Study Site}

The LRB is located at the northern Haihe River Basin, with geographical scope of $39^{\circ} 10^{\prime}-42^{\circ} 30^{\prime}$ N, $115^{\circ} 30^{\prime}-119^{\circ} 15^{\prime} \mathrm{E}$ (Figure 2). As one of the four major rivers in the Haihe River Basin, the Luanhe River flows through 27 cities and countries in Hebei Province, Inner Mongolia Autonomous Region and Liaoning Province, with watershed area of approximately $44,750 \mathrm{~km}^{2}$. The elevation of the LRB decreases from north to south, with a landform of plateau, mountains and plain, respectively [34,35].

The LRB experiences a humid, semi-humid, and semi-arid temperate continental monsoon climate from southeast to northwest. The region has the characteristics of four distinct seasons, significant monsoon, concentrated precipitation, rain and heat over the same period, and a complex climate. The multi-year average water surface evaporation in the basin is approximately 950 to $1150 \mathrm{~mm}$. The annual precipitation of the LRB is between 390 to $800 \mathrm{~mm}$, with significant heterogeneous seasonal distribution. The precipitation is concentrated in summer, of 260 to $560 \mathrm{~mm}$, accounting for $67 \%$ to $76 \%$ of the annual precipitation. Thus, DFAA typically occurs at the turn of spring to summer. 


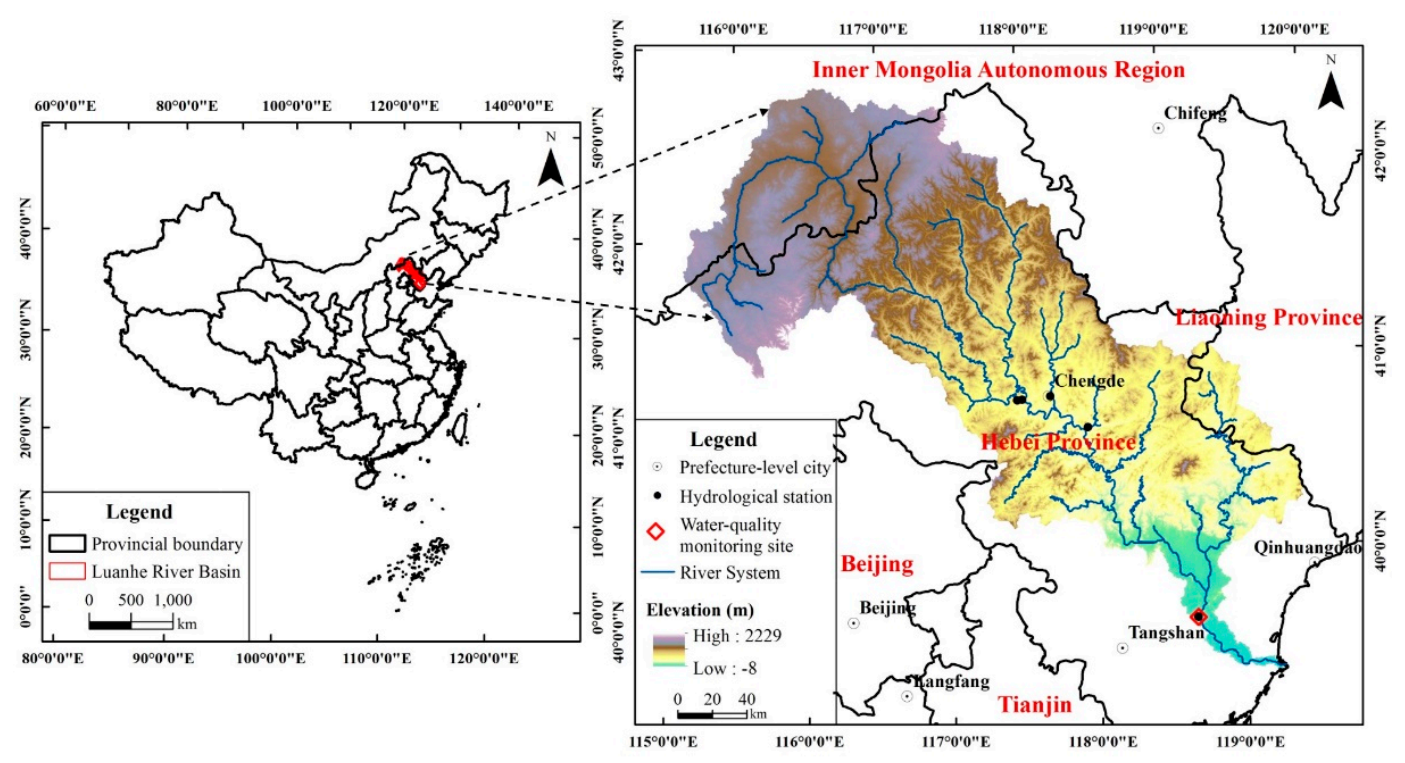

Figure 2. The Luanhe River Basin.

\subsection{RCPs and SWAT Model}

Future climate predictions are based on the scenarios considering the emissions of greenhouse gases and aerosols. Representative concentration pathways (RCP) are climate scenarios developed in the Intergovernmental Panel on Climate Change (IPCC) Fifth Assessment Report, including RCP2.6, RCP4.5, RCP6.0, and RCP8.5. According to existing research [36,37], three climate scenarios-RCP2.6, RCP4.5, and RCP8.5-were selected as future climate prediction scenario models to analyze future climate change in the LRB from 2020 to 2050. RCP2.6 is the scenario that limits the average temperature increase lower than $2.0^{\circ} \mathrm{C}$, and the radiative forcing peak appears before 2100 then drops to $2.6 \mathrm{~W} \cdot \mathrm{m}^{-2}$ in 2100 . $\mathrm{RCP} 4.5$ is to stabilize the radiative forcing at $4.5 \mathrm{~W} \cdot \mathrm{m}^{-2}$. RCP8.5 assumes the largest population, a low rate of technological innovation and slow energy improvement, with the highest greenhouse gas emission, the radiative forcing rises to $8.5 \mathrm{~W} \cdot \mathrm{m}^{-2}$ in 2100 . Each climate scenario was based on the interpolated, revised results of five sets of global climate scenarios (GFDL-ESM2M, HADGEM2-ES, IPSL-CM5A-LR, MIROC-ESM-CHEM and NORESM1-M) provided by the Inter-Sectoral Impact Model Inter-comparison Project (ISI-MIP). The evaluation and optimization of climate prediction scenario models have been described in earlier studies [36,37].

ArcSWAT2012 (a public domain model jointly developed by the United States Department of Agriculture (USDA) Agricultural Research Service and Texas A\&M AgriLife Research), as a distributed hydrological model, has been widely used to assess the long-term impacts of different climatic conditions and land cover changes on sediment, nutrients and so on. In this study, the LRB was divided into 88 sub-basins, with the smallest catchment area threshold defined as $250 \mathrm{~km}^{2}$. The model construction, calibration, and validation are essential and complex. The transformation of different databases [36,38-40], the model construction [36], the calibration and validation details of the hydrological process [36,41] and the surface water quality [42] can be found in the corresponding references.

Precipitation and temperature are considered as the main elements of future climate change in this paper. It is assumed that the future point source emissions, withdrawn water, cultivated land areas, and irrigation systems are maintained at the current level.

\subsection{Data Sources}

To explore the evolution characteristics of the DFAA and its impacts on surface water quality in the LRB from 2020 to 2050, this study applied representative concentration pathways (RCPs) for future climate prediction and the SWAT model for surface water quality simulation. The input 
data mainly contains four types, which are topography, meteorology, hydrology, and water quality. The topographical data include digital elevation models (DEM), land use and soil. The meteorological data include the historical daily data from 1963 to 2017, and future prediction data from 2020 to 2050, based on the simulation results of a future climate prediction scenario model. The hydrological data include the monthly observed flow data from 1970 to 2000 on five hydrological stations. The surface water quality data include monthly measurements of TN and TP, from 2015 to 2017 in the downstream water quality monitoring site, Luanxian Station. The samples were analyzed on the basis of the Environmental Quality Standards for Surface Water (GB3838-2002) [43]. The specific information of the data is shown in Table 1.

Table 1. The database and main sources.

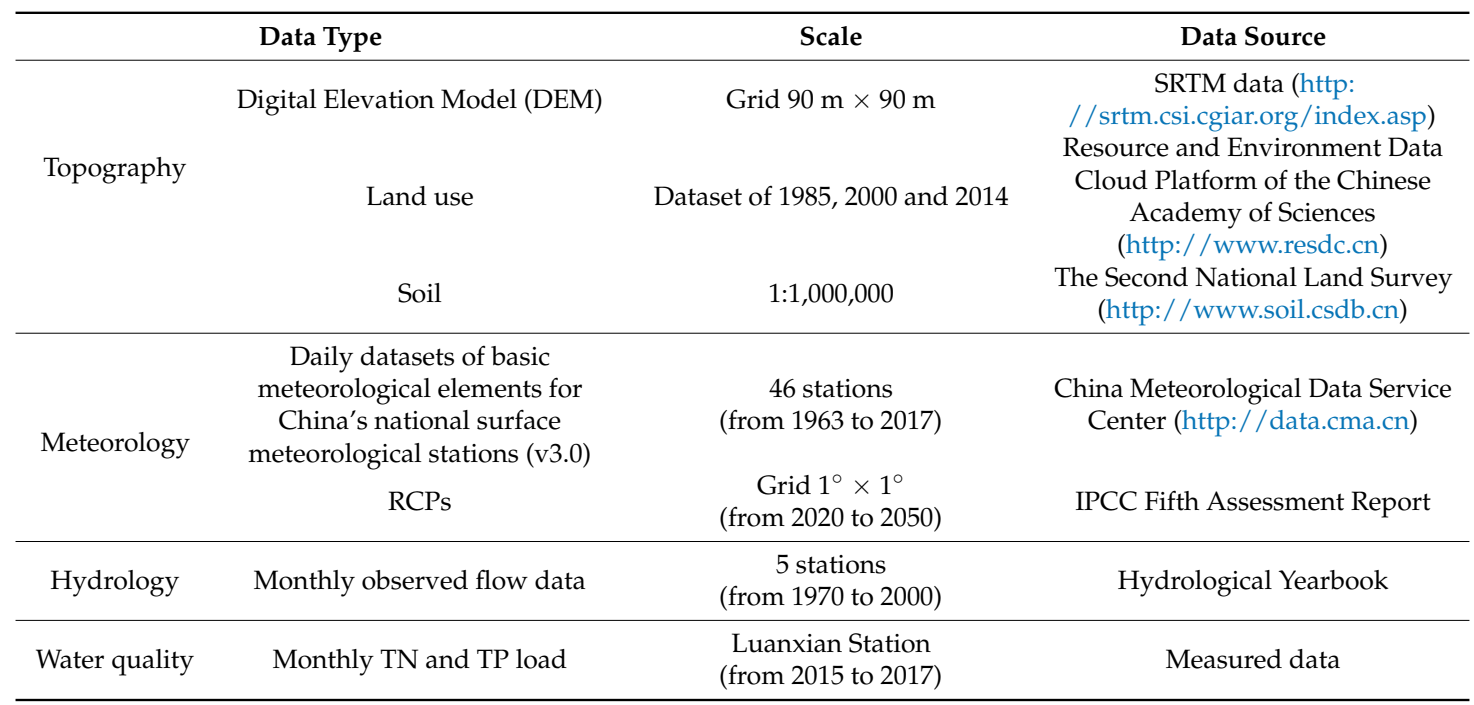

SRTM represents the Shuttle Radar Topography Mission; RCPs represents the representative concentration pathways;

TN refers to total nitrogen; TP refers to total phosphorus.

\subsection{Data Analysis}

\subsubsection{Evaluation of DFAA}

The analysis of DFAA is based on the daily precipitation data, which includes three steps: Dividing the drought levels, classifying the flood levels, and determining the DFAA levels.

The number of continuous rainless days is used to identify the drought period and the drought level. The classification criteria are determined by the Standard of Classification for Drought Severity (SL424-2008) (Table 2) [44]. A rainless day refer to the daily precipitation amount less than $3 \mathrm{~mm}$, $5 \mathrm{~mm}, 3 \mathrm{~mm}$ and $3 \mathrm{~mm}$ in spring (March to May), summer (June to August), autumn (September to November), and winter (December to February), respectively. If there are rainless days across the season, the drought level is determined by the season with more than half of the rainless days.

Table 2. Standard of classification for drought severity.

\begin{tabular}{cccc}
\hline \multirow{2}{*}{ Season } & \multicolumn{3}{c}{ Continuous Rainless Days (d) } \\
\cline { 2 - 4 } & Light Drought & Moderate Drought & Severe Drought \\
\hline Spring (Mar. to May) & $15-30$ & $31-50$ & $>51$ \\
Summer (Jun. to Aug.) & $10-20$ & $21-30$ & $>31$ \\
Autumn (Sept. to Nov.) & $15-30$ & $31-50$ & $>51$ \\
Winter (Dec. to Feb.) & $20-30$ & $31-60$ & $>61$ \\
\hline
\end{tabular}

The flood levels are determined by the total precipitation amount within 5 days after the droughts. In one precipitation process, when the precipitation amount far exceeds the infiltration amount, it is 
considered that a flood will occur. The infiltration amount is the product of the precipitation amount and the infiltration coefficient. The main characteristic of the DFAA is the sudden change from drought to flood. Therefore, the DFAA is mainly concerned with the flood caused by the short-term and intensive precipitation processes. When classifying the flood level, the annual maximum $n$-day precipitation is applied to calculate the threshold of infiltration in the DFAA (Equation (1)).

$$
I_{n}=\alpha P_{n}
$$

where $I_{n}$ is the infiltration amount of continuous precipitation for $n$ days, mm. $n$ is the number of continuous rainy days. $\alpha$ is the infiltration coefficient, mainly affected by precipitation, groundwater depth, underlying surface conditions, and evaporation. Previous studies show the infiltration coefficient is about 0.23 in the North China Plain and the Huang-Huai-Hai Plain, i.e., $\alpha$ equals to 0.23 in this study [45]. $P_{n}$ is the multi-year average of the annual maximum n-day precipitation, $\mathrm{mm}$. To calculate $P_{n}$, we analyzed the historical meteorological data (from 1963 to 2017) of 46 meteorological stations in and around the LRB, and obtained the infiltration amount of continuous $n$-days precipitation $\left(I_{n}\right)$.

To determine the DFAA levels, the key issue is to classify the flood levels. The flood levels are based on the precipitation threshold, which is in accordance with the infiltration threshold. Equations (2) and (3) calculate the precipitation threshold.

$$
\begin{gathered}
P T_{j n}=k I_{n} \\
k=k_{0}+j+\beta(n-1)
\end{gathered}
$$

where $P T_{j n}$ is the precipitation threshold, mm. $j$ is the flood level, when $j$ is equal to 0,1 , and 2 , the corresponding flood level is light flood, moderate flood, and severe flood. $k_{0}$ is an undetermined coefficient. Referring to the historical flood data of the LRB, when $k_{0}=3$, it is considered that the daily precipitation in the basin reaches the light flood level. $k$ is the corrected value of $k_{0}$, related to the flood level and cumulative rainy days. $\beta$ is an undetermined coefficient, when $j$ is equal to 0,1 , and $2, \beta$ is equal to $0.5,0.7$, and 1 , respectively.

The grade of DFAA is judged according to the drought level and the precipitation level after drought. The combination of three drought levels and three flood levels can give nine types of DFAA. The specific types are shown in Table 3.

Table 3. The combination types of drought-flood abrupt alternation.

\begin{tabular}{cccc}
\hline Level & Light Flood (LF) 1 & Moderate Flood (MF) 2 & Severe Flood (SF) 3 \\
\hline Light drought (LD) 1 & LD-LF 1 & LD-MF 1.5 & LD-SF 2 \\
Moderate drought (MD) 2 & MD-LF 1.5 & MD-MF 2 & MD-SF 2.5 \\
Severe drought (SD) 3 & SD-LF 2 & SD-MF 2.5 & SD-SF 3 \\
\hline
\end{tabular}

Based on the types of DFAA, droughts and floods are assigned to the scales 1, 2, and 3 to correspond with the level of light, moderate, and severe, respectively. The DFAA level is judged by the average value of drought level and flood level (Table 3). When the average value is lower than 2, equal to 2, and larger than 2, the DFAA occurs in light level (light drought-light flood, light drought-moderate flood, moderate drought-light flood), moderate level (light drought-severe flood, moderate drought-moderate flood, severe drought-light flood), and severe level (moderate drought-severe flood, severe drought-moderate flood, severe drought-severe flood), respectively. The higher the level, the more serious the DFAA.

\subsubsection{Evaluation of DFAA Impacts on Surface Water Quality}

The incidence of water pollution was applied to assess the surface water quality situation, which is a single-factor evaluation method. In this study, TN and TP were chosen as the surface water indicators. 
According to the Environmental Quality Standards for Surface Water (GB3838-2002), the concentration threshold of TN in Class III (water quality is applicable to secondary reserve of centralized drinking water sources, general fish protection areas and swimming areas) and Class IV (water quality is applicable to general industrial protection areas and recreational areas with indirect contact to humans) is $1.0 \mathrm{mg} / \mathrm{L}$, and $1.5 \mathrm{mg} / \mathrm{L}$, respectively; the concentration threshold of TP in Class III and Class IV is $0.2 \mathrm{mg} / \mathrm{L}$, and $0.3 \mathrm{mg} / \mathrm{L}$, respectively. For the unified analysis, the surface water can be considered contaminated with TN and TP concentrations greater than Class IV. Meanwhile, we analyzed the TN and TP pollutions with concentrations greater than Class III. Equation (4) calculates the incidence of water pollution.

$$
p=\frac{n_{p}}{N}
$$

where $p$ is the incidence of water pollution, $n_{p}$ is the number of polluted months during the study period, $N$ is the total number of months.

To assess the DFAA impacts on TN and TP, the incidence of water pollution was explored in DFAA months, normal months (without DFAA), and total months, respectively. To further study the impacts of different DFAA levels on TN and TP pollution, the incidence of water pollution in DFAA months under different levels was calculated.

\section{Results}

\subsection{Model Calibration and Validation}

The flow data of five hydrological stations (Figure 2) was applied for the hydrologic calibration and validation process in the SWAT model. As the Luanxian Station is the monitoring station for both hydrology and water quality (Figure 2), the hydrological calibration and validation results of this station are plotted with the article length limit. For the hydrological process, $R^{2}$ and NSE were 0.95 and 0.95 during the calibration period, and 0.95 and 0.94 during the validation period (Figure 3a). The measured water quality data, from 2015 to 2017, were applied for the calibration and validation of TN and TP. Figure $3 b, c)$ show the water quality calibration and validation results. For TN, $R^{2}$ and NSE were 0.64 and 0.58 , during the calibration period, and 0.52 and 0.42 , during the validation period. For TP, $\mathrm{R}^{2}$ and NSE were 0.79 and 0.74 , during the calibration period, and 0.86 and 0.74 , during the validation period.

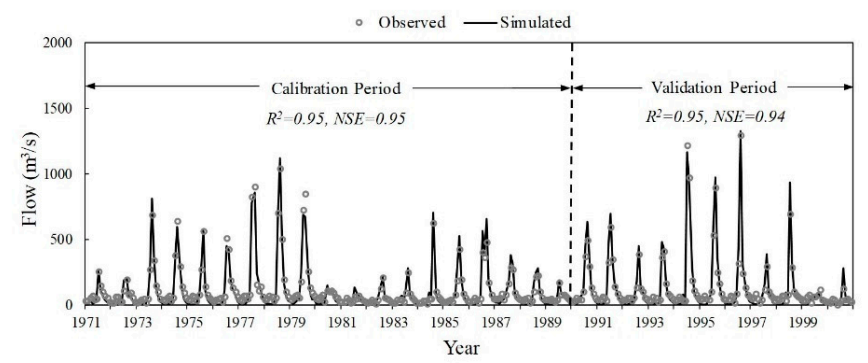

(a)

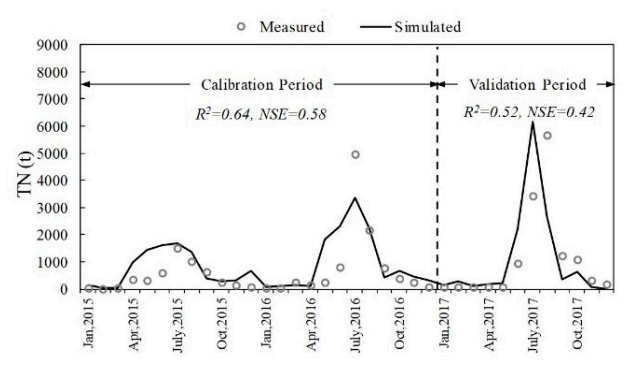

(b)

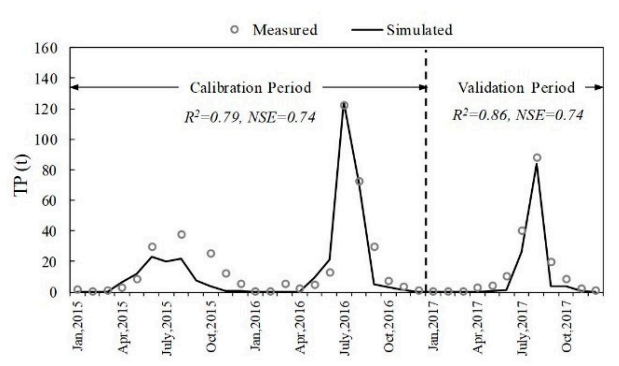

(c)

Figure 3. The Soil and Water Assessment Tool (SWAT) model calibration and validation results of (a) hydrological process of the Luanxian Station; (b) total nitrogen (TN) load; (c) total phosphorus (TP) load. 


\subsection{Determination of DFAA Levels in the LRB}

Table 4 shows the calculation results of the $I_{n}$ of $n$-days precipitation in the LRB. The $I_{n}$ of continuous 1-day, 2-days, 3-days, 4-days, and 5-days precipitation in the LRB is $17 \mathrm{~mm}, 18 \mathrm{~mm}, 19 \mathrm{~mm}$, $20 \mathrm{~mm}$, and $22 \mathrm{~mm}$, respectively.

Table 4. The infiltration amount of continuous $n$-days precipitation in the Luanhe River Basin.

\begin{tabular}{cccccc}
\hline $\boldsymbol{n}(\mathbf{d})$ & $\mathbf{1}$ & $\mathbf{2}$ & $\mathbf{3}$ & $\mathbf{4}$ & $\mathbf{5}$ \\
\hline$I_{n}(\mathrm{~mm})$ & 17 & 18 & 19 & 20 & 22
\end{tabular}

$n$ is the number of continuous rainy days; $I_{n}$ is the infiltration amount of continuous $n$-days precipitation.

According to Equations (1)-(3), the classification of flood levels in the LRB can be obtained (Table 5). The lower limit of light flood level for continuous 1-day, 2-days, 3-days, 4-days, and 5-days precipitation in the LRB is $50 \mathrm{~mm}, 60 \mathrm{~mm}, 75 \mathrm{~mm}, 90 \mathrm{~mm}$, and $110 \mathrm{~mm}$, respectively. The lower limit of moderate flood level for continuous 1-day, 2-days, 3-days, 4-days, and 5-days precipitation in the LRB is $70 \mathrm{~mm}, 85 \mathrm{~mm}, 100 \mathrm{~mm}, 120 \mathrm{~mm}$, and $150 \mathrm{~mm}$, respectively. The lower limit of severe flood level for continuous 1-day, 2-days, 3-days, 4-days, and 5-days precipitation in the LRB is $85 \mathrm{~mm}, 110 \mathrm{~mm}, 130$, $\mathrm{mm} 160 \mathrm{~mm}$, and $200 \mathrm{~mm}$, respectively. When the continuous $n$-days precipitation is larger than the lower limit of the three flood levels, it is considered that the floods occur in distinctive levels.

Table 5. The classification of flood levels in the Luanhe River Basin.

\begin{tabular}{cccccc}
\hline $\boldsymbol{n} \mathbf{( d )}$ & $\mathbf{1}$ & $\mathbf{2}$ & $\mathbf{3}$ & $\mathbf{4}$ & $\mathbf{5}$ \\
\hline Light flood & 50 & 60 & 75 & 90 & 110 \\
Moderate flood & 70 & 85 & 100 & 120 & 150 \\
Severe flood & 85 & 110 & 130 & 160 & 200 \\
\hline \multicolumn{7}{c}{$n$ is the number of continuous rainy days. }
\end{tabular}

Combining the Standard of Classification for Drought Severity shown in Table 2, the DFAA levels in the LRB can be determined. In details, the light DFAA refers to the combination of light drought-light flood, light drought-moderate flood, and moderate drought-light flood; the moderate DFAA refers to the combination of light drought-severe flood, moderate drought-moderate flood, and severe drought-light flood; the severe DFAA refers to the combination of mild drought-severe flood, severe drought-mild flood, and severe drought-severe flood.

\subsection{Evolution Characteristics of DFAA}

\subsubsection{DFAA in Different Seasons}

As the Standard of Classification for Drought Severity varies in different seasons, we conducted the analysis of DFAA in different seasons. Under different RCPs, the frequencies of DFAA were not the same. However, from 2020 to 2050, under all three RCPs selected, there were no DFAA events in winter, most of the DFAA events occurred in summer, and few DFAA events in spring or autumn. There were two DFAA events occurring in spring and autumn under RCP2.6, and one or two DFAA occurring in autumn under RCP4.5, and RCP8.5, respectively. The frequency of DFAA increased from northwest to southeast both in each season and in the whole year. Most of the DFAA was concentrated in the lower reaches of the LRB. Figure 3 plots the specific information about the distribution of DFAA events, from 2020 to 2050, in the LRB.

In summer, under RCP2.6, the frequency of DFAA events was zero to two in the upper and middle reaches of the LRB, and varied from three to nine in the downstream (Figure 4(a1)). Under RCP4.5, there were, zero to two, three to five, and six to fourteen DFAA events in the upstream, midstream, 
and downstream, respectively. The most DFAA occurred in the eastern part of the LRB (Figure 4(b1)). Under RCP 8.5, the frequency of DFAA was zero or one, two to four, five to eight in the upper, middle and lower reaches of the LRB, respectively. The high frequency of DFAA was located in the east and south of the basin (Figure $4(\mathrm{c} 1)$ ).

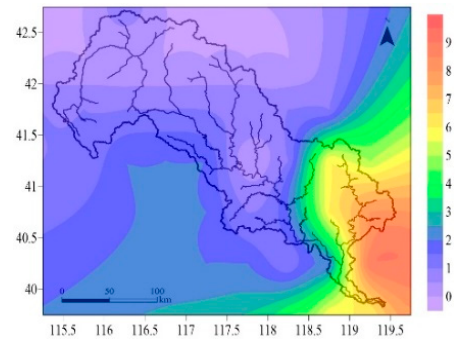

(a1)

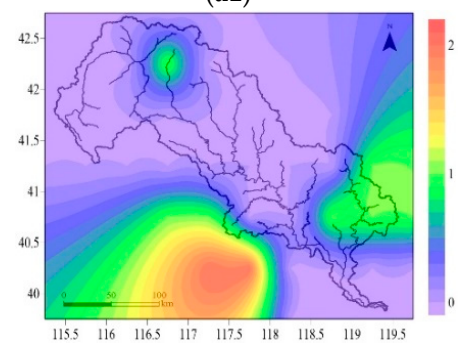

(a2)

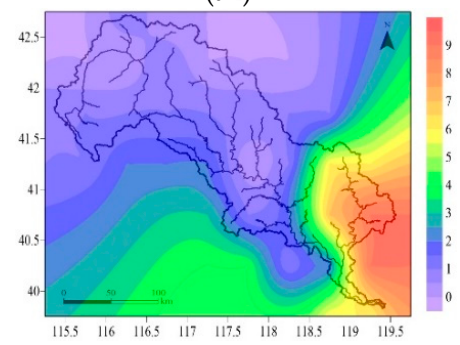

(a3)

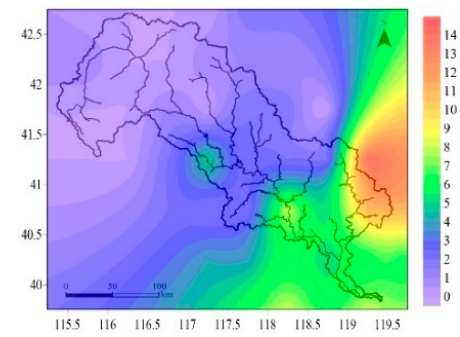

(b1)

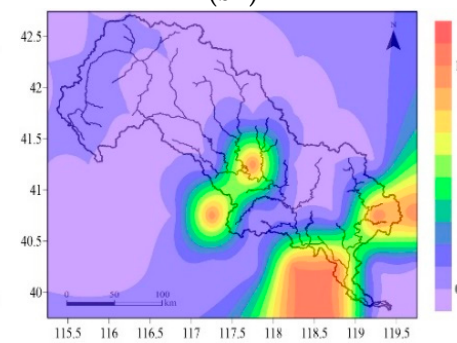

(b2)

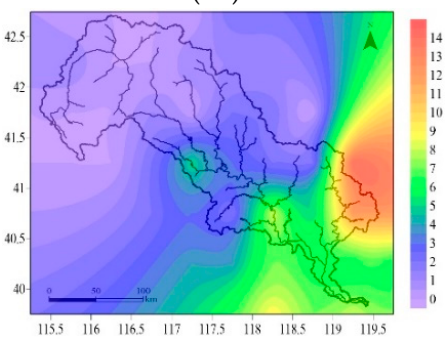

(b3)

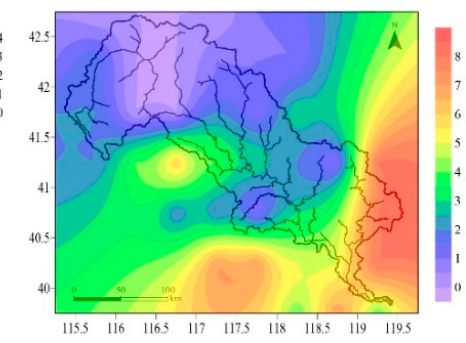

(c1)

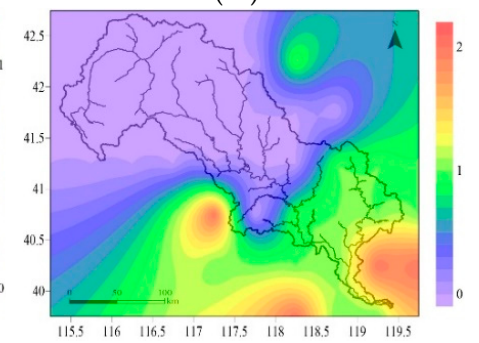

(c2)

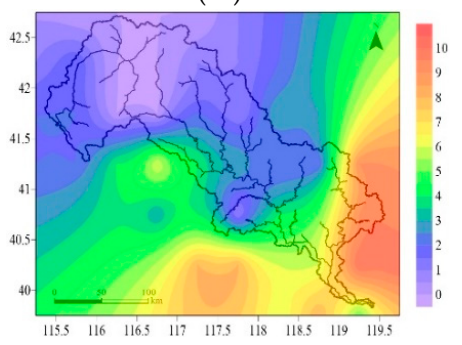

(c3)

Figure 4. Distribution of drought-flood abrupt alternation events from 2020 to 2050 in the Luanhe River Basin: In summer under RCP2.6 (a1), RCP4.5 (b1), and RCP8.5 (c1); in spring and autumn under RCP2.6 (a2), in autumn under RCP4.5 (b2) and RCP8.5 (c2); in whole year under RCP2.6 (a3), RCP4.5 (b3), and RCP8.5 (c3). RCPs represent the Representative Concentration Pathways. The color bars represent the occurrence frequency of drought-flood abrupt alternation events, for example, the purple means the frequency is zero.

In spring and autumn, under RCP2.6, there were almost no DFAA, with one in the northern and eastern part, and one to two in the southern part (Figure 4(a2)). In autumn, under RCP4.5, there was one DFAA in the midstream and downstream (Figure 4(b2)). Under RCP8.5, the frequency of DFAA was zero in the upper and middle reaches of the LRB, while one or two in the downstream (Figure 4(c2)).

On an annual scale, the evolution laws of DFAA were approximately the same as those in summer. Under RCP2.6, there were zero to two DFAA events occurring in the upper and middle reaches of the LRB. The frequency varied from three to nine in the downstream (Figure 4(a3)). Under RCP4.5, the frequency of DFAA was zero to two, three to five, and six to fourteen DFAA events in the upstream, midstream, and downstream, respectively. The most DFAA occurred in the east of the LRB (Figure 4(b3)). Under RCP8.5, there were zero or one, two to four, five to eight DFAA events occurring in the upper, middle and lower reaches of the LRB, respectively (Figure 4(c3)). 


\subsubsection{DFAA in Different Levels}

In this study, the DFAA events in the LRB were classified on three levels. The frequency evolution laws of DFAA had differences under three RCPs. The same as the evolution characteristics in different seasons, the frequency of DFAA increased from northwest to southeast in all three DFAA levels. The DFAA events occurred more frequently in the lower reaches of the LRB. Meanwhile, most of the DFAA events were in light level. Figure 4 shows the distribution of DFAA events in different levels from 2020 to 2050 in the LRB.

For the light DFAA level, under RCP2.6, the frequency of DFAA events was zero or one in the upstream, one or two in the middle reaches of the LRB, and varied from four to nine in the downstream (Figure 5(a1)). Under RCP4.5, there were zero or one, two to four, and five to nine DFAA events in the upstream, midstream, and downstream, respectively (Figure 5(b1)). Under RCP8.5, the frequency of DFAA was zero or one, two to four, five to eight in the upper, middle and lower reaches of the LRB, respectively. The high frequency of DFAA was located in the eastern and southern part (Figure 5(c1)).

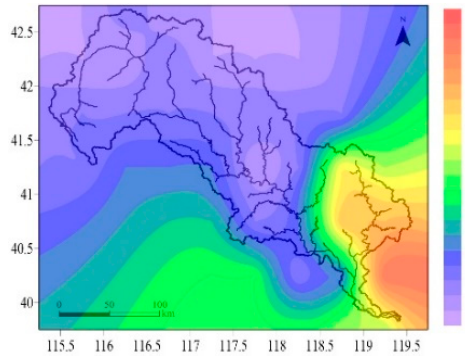

(a1)

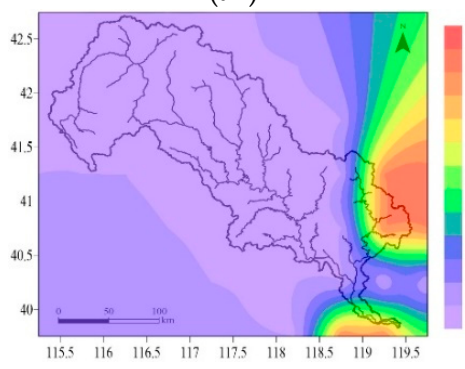

(a2)

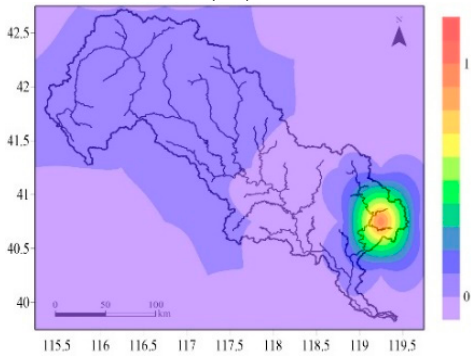

(a3)

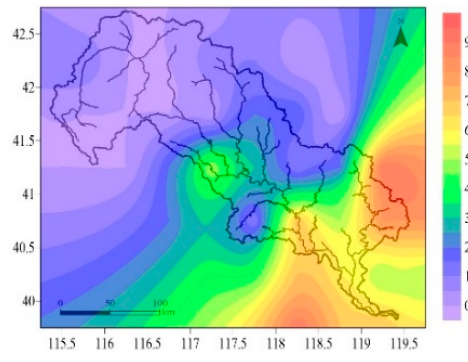

(b1)

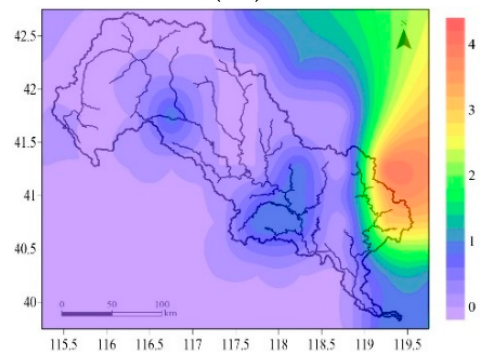

(b2)

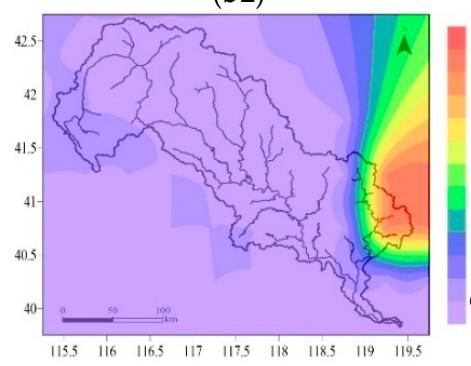

(b3)

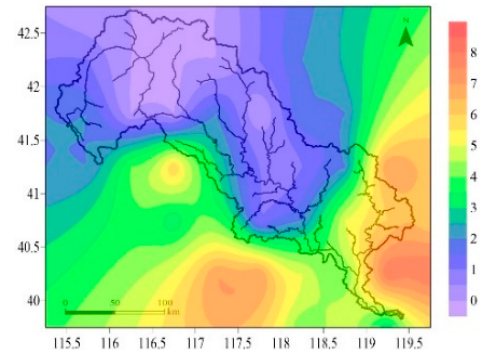

(c1)

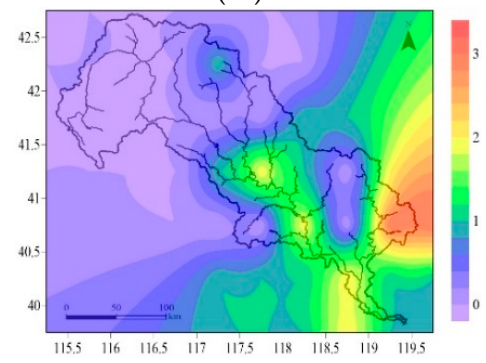

(c2)

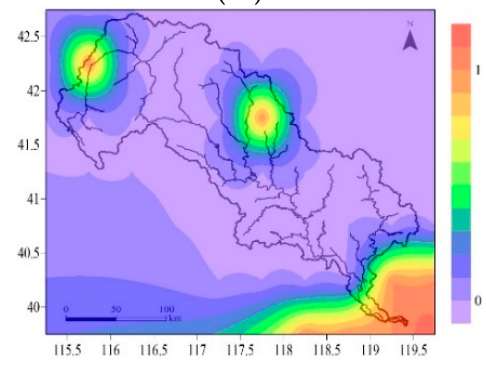

(c3)

Figure 5. Distribution of drought-flood abrupt alternation events, from 2020 to 2050, in the Luanhe River Basin: In light level under RCP2.6 (a1), RCP4.5 (b1) and RCP8.5 (c1); in moderate level under RCP2.6 (a2), RCP4.5 (b2), and RCP8.5 (c2); in severe level under RCP2.6 (a3), RCP4.5 (b3), and RCP8.5 (c3). RCPs represents the representative concentration pathways. The color bars represent the occurrence frequency of drought-flood abrupt alternation events, for example, the purple means the frequency is zero.

For the moderate DFAA level, under RCP2.6, there was almost no DFAA in the upper or the middle reaches of the LRB, while there were one or two in the downstream, especially in the north and 
east of the basin (Figure 5(a2)). Under RCP4.5, the frequency of DFAA in the upstream, midstream and downstream was zero or one, zero or one, and one to four, respectively (Figure 5(b2)). Under RCP8.5, there were zero or one, one or two, and zero to three DFAA in the upper, middle, and lower reaches of the LRB, respectively (Figure 5(c2)).

For severe DFAA level, there was almost no occurrence possibility of DFAA events. Under RCP2.6 and RCP4.5, there were almost no DFAA in the upstream and midstream, but one in the eastern downstream (Figure 5(a3),(b3)). Under RCP8.5, maybe one DFAA event could have occurred in the northern part of both the upstream and midstream, also the outlet of the basin in the downstream (Figure 5(c3)).

\subsection{The Relationship between DFAA and Water Quality}

The incidence of water pollution was analyzed to reveal the relationship between DFAA and indicators of water quality. Table 6 plots the incidence of water pollution, based on the Environmental Quality Standards for Surface Water (GB3838-2002) of Class IV under three RCPs. We calculated the incidence of water pollution in the condition of DFAA months, normal months and total months. The incidence of TN pollution, TP pollution, simultaneous occurrence of TN and TP pollution showed similar variation laws in all RCPs, that is, the incidence of pollution increased according to the following order: Normal months $<$ total months $<$ DFAA months. The incidence of TN pollution was much larger than the incidence of TP pollution and the simultaneous occurrence of TN and TP pollution, indicating that TN pollution is more serious than TP pollution in the LRB. For TN pollution, the incidence of pollution was $94.6 \%$ to $97.3 \%, 67.5 \%$ to $69.3 \%$, and $70.2 \%$ to $72.3 \%$ in DFAA months, normal months, and total months, respectively. For TP pollution, in RCP4.5, the incidence of pollution was $2.9 \%$, $0.6 \%$, and $0.8 \%$ in DFAA months, normal months, and total months, respectively. The incidence of TP pollution and simultaneous occurrence of TN and TP pollution was the same in DFAA months, normal months and total months, which reveals that when TP pollution occurs, the TN pollution occurs simultaneously. In RCP2.6 and RCP8.5, there was no possibility of TP pollution and simultaneous occurrence of TN and TP pollution.

Table 6. The incidence of water pollution (\%) in Class IV under different months.

\begin{tabular}{|c|c|c|c|c|c|c|c|c|c|}
\hline \multirow[b]{2}{*}{ Scenario } & \multicolumn{3}{|c|}{ TN Pollution } & \multicolumn{3}{|c|}{ TP Pollution } & \multicolumn{3}{|c|}{ TN and TP Pollution } \\
\hline & $\begin{array}{c}\text { DFAA } \\
\text { Months }\end{array}$ & $\begin{array}{l}\text { Normal } \\
\text { Months }\end{array}$ & $\begin{array}{c}\text { Total } \\
\text { Months }\end{array}$ & $\begin{array}{c}\text { DFAA } \\
\text { Months }\end{array}$ & $\begin{array}{l}\text { Normal } \\
\text { Months }\end{array}$ & $\begin{array}{c}\text { Total } \\
\text { Months }\end{array}$ & $\begin{array}{c}\text { DFAA } \\
\text { Months }\end{array}$ & $\begin{array}{l}\text { Normal } \\
\text { Months }\end{array}$ & $\begin{array}{c}\text { Total } \\
\text { Months }\end{array}$ \\
\hline RCP2.6 & $97.30 \%$ & $69.25 \%$ & $72.04 \%$ & $0.00 \%$ & $0.00 \%$ & $0.00 \%$ & $0.00 \%$ & $0.00 \%$ & $0.00 \%$ \\
\hline $\mathrm{RCP} 4.5$ & $97.14 \%$ & $69.73 \%$ & $72.31 \%$ & $2.86 \%$ & $0.59 \%$ & $0.81 \%$ & $2.86 \%$ & $0.59 \%$ & $0.81 \%$ \\
\hline RCP8.5 & $94.59 \%$ & $67.46 \%$ & $70.16 \%$ & $0.00 \%$ & $0.00 \%$ & $0.00 \%$ & $0.00 \%$ & $0.00 \%$ & $0.00 \%$ \\
\hline
\end{tabular}

Table 7 shows the incidence of water pollution with the water quality standard of Class III under three RCPs, the variation laws were the same as the pollution incidence with the standard of Class IV. The incidence of TN pollution, TP pollution, simultaneous occurrence of TN and TP pollution showed similar variation laws in all RCPs, with increasing order: Normal months $<$ total months $<$ DFAA months. The incidence of TN pollution was much larger than the incidence of TP pollution and simultaneous occurrence of TN and TP pollution. The incidence of the TP pollution, and simultaneous occurrence of TN and TP pollution was approximate. For TN pollution, the incidence of pollution was $97.1 \%$ to $97.3 \%, 77.0 \%$ to $77.5 \%$, and $78.5 \%$ to $79.3 \%$ in DFAA months, normal months, and total months, respectively. For TP pollution, the incidence of pollution was $8.1 \%$ to $13.5 \%, 0.9 \%$ to $1.5 \%$, and $1.6 \%$ to $2.7 \%$ in DFAA months, normal months, and total months, respectively. The incidence of TP pollution and simultaneous occurrence of TN and TP pollution was the same in DFAA months, normal months and total months, respectively. We can see that the possibility of TN pollution exceeding Class III in the LRB was much more serious than TP pollution. Meanwhile, when TP pollution occurs, the TN pollution occurs simultaneously. 
Table 7. The incidence of water pollution (\%) in Class III under different months.

\begin{tabular}{|c|c|c|c|c|c|c|c|c|c|}
\hline \multirow[b]{2}{*}{ Scenario } & \multicolumn{3}{|c|}{ TN Pollution } & \multicolumn{3}{|c|}{ TP Pollution } & \multicolumn{3}{|c|}{ TN and TP Pollution } \\
\hline & $\begin{array}{c}\text { DFAA } \\
\text { Months }\end{array}$ & $\begin{array}{l}\text { Normal } \\
\text { Months }\end{array}$ & $\begin{array}{c}\text { Total } \\
\text { Months }\end{array}$ & $\begin{array}{c}\text { DFAA } \\
\text { Months }\end{array}$ & $\begin{array}{l}\text { Normal } \\
\text { Months }\end{array}$ & $\begin{array}{c}\text { Total } \\
\text { Months }\end{array}$ & $\begin{array}{c}\text { DFAA } \\
\text { Months }\end{array}$ & $\begin{array}{l}\text { Normal } \\
\text { Months }\end{array}$ & $\begin{array}{l}\text { Total } \\
\text { Months }\end{array}$ \\
\hline RCP2.6 & $97.30 \%$ & $76.42 \%$ & $78.49 \%$ & $13.51 \%$ & $1.49 \%$ & $2.69 \%$ & $13.51 \%$ & $1.49 \%$ & $2.69 \%$ \\
\hline RCP4.5 & $97.14 \%$ & $77.45 \%$ & $79.30 \%$ & $11.43 \%$ & $1.48 \%$ & $2.42 \%$ & $11.43 \%$ & $1.48 \%$ & $2.42 \%$ \\
\hline RCP8.5 & $97.30 \%$ & $77.01 \%$ & $79.03 \%$ & $8.11 \%$ & $0.90 \%$ & $1.61 \%$ & $8.11 \%$ & $0.90 \%$ & $1.61 \%$ \\
\hline
\end{tabular}

Table 8 presents the incidence of water pollution with the water quality standard of Class IV under different DFAA levels. The incidence of TN pollution showed similar variation laws in all RCPs, that is, the incidence of pollution increased according to the following order: Light DFAA < moderate DFAA = severe DFAA. While the incidence of TP pollution and simultaneous occurrence of TN and TP pollution was much lower. For TN pollution, the incidence of pollution was $92.96 \%$ to $97.1 \%, 100 \%$, and $100 \%$ in light DFAA, moderate DFAA, and severe DFAA, respectively. It can be inferred that when DFAA occurs, the TN pollution almost occurs simultaneously. For TP pollution, in RCP4.5, the incidence of pollution was $3.7 \%, 0.0 \%$, and $0.0 \%$ in light DFAA, moderate DFAA, and severe DFAA, respectively. The incidence of TP pollution, and the simultaneous occurrence of TN and TP pollution, was the same in light DFAA, moderate DFAA, and severe DFAA, which reveals that when TP pollution occurs, the TN pollution occurs simultaneously. In RCP2.6 and RCP8.5, there was no possibility of TP pollution and simultaneous occurrence of TN and TP pollution under different DFAA levels.

Table 8. The incidence of water pollution (\%) in Class IV under different DFAA levels.

\begin{tabular}{cccccccccc}
\hline \multirow{2}{*}{ Scenario } & \multicolumn{3}{c}{ TN Pollution } & \multicolumn{3}{c}{ TP Pollution } & \multicolumn{2}{c}{ TN and TP Pollution } \\
\cline { 2 - 10 } & $\begin{array}{c}\text { Light } \\
\text { DFAA }\end{array}$ & $\begin{array}{c}\text { Moderate } \\
\text { DFAA }\end{array}$ & $\begin{array}{c}\text { Severe } \\
\text { DFAA }\end{array}$ & $\begin{array}{c}\text { Light } \\
\text { DFAA }\end{array}$ & $\begin{array}{c}\text { Moderate } \\
\text { DFAA }\end{array}$ & $\begin{array}{c}\text { Severe } \\
\text { DFAA }\end{array}$ & $\begin{array}{c}\text { Light } \\
\text { DFAA }\end{array}$ & $\begin{array}{c}\text { Moderate } \\
\text { DFAA }\end{array}$ & $\begin{array}{c}\text { Severe } \\
\text { DFAA }\end{array}$ \\
\hline RCP2.6 & $97.14 \%$ & $100.00 \%$ & $100.00 \%$ & $0.00 \%$ & $0.00 \%$ & $0.00 \%$ & $0.00 \%$ & $0.00 \%$ & $0.00 \%$ \\
RCP4.5 & $96.30 \%$ & $100.00 \%$ & $100.00 \%$ & $3.70 \%$ & $0.00 \%$ & $0.00 \%$ & $3.70 \%$ & $0.00 \%$ & $0.00 \%$ \\
RCP8.5 & $92.86 \%$ & $100.00 \%$ & $100.00 \%$ & $0.00 \%$ & $0.00 \%$ & $0.00 \%$ & $0.00 \%$ & $0.00 \%$ & $0.00 \%$ \\
\hline
\end{tabular}

It can be discerned that the variation laws of the incidence of water pollution with the water quality standard of Class III under different DFAA levels were similar to the pollution incidence with the standard of Class IV (Table 9). The incidence of TN pollution showed the same variation laws in all RCPs, with increasing order: Light DFAA $<$ moderate DFAA = severe DFAA. The incidence of TN pollution was much larger than the incidence of TP pollution and the simultaneous occurrence of TN and TP pollution. The incidence of TP pollution and simultaneous occurrence of TN and TP pollution were approximate. For TN pollution, the incidence of pollution was $92.9 \%$ to $97.1 \%$, $100.0 \%$, and $100.0 \%$ in light DFAA, moderate DFAA, and severe DFAA, respectively. For TP pollution, the incidence of pollution varied differently in the three RCPs, with the same variation in RCP2.6 and RCP4.5. In RCP2.6 and RCP4.5, the incidence of TP pollution in light DFAA level was 14.3\%, and $14.8 \%$, respectively; while both $0.0 \%$ in moderate DFAA level and severe DFAA level. In RCP8.5, the incidence of TP pollution was $0.00 \%, 16.7 \%$, and $66.7 \%$ in light DFAA, moderate DFAA, and severe DFAA, respectively. The variation laws of the incidence of simultaneous occurrence of TN and TP pollution were the same to that of TP pollution. Obviously, the possibility of TN pollution exceeding Class III in the LRB was much more serious than TP pollution. Meanwhile, when TP pollution occurs, TN pollution occurs simultaneously. 
Table 9. The incidence of water pollution (\%) in Class III under different DFAA levels.

\begin{tabular}{cccccccccc}
\hline \multirow{2}{*}{ Scenario } & \multicolumn{3}{c}{ TN Pollution } & \multicolumn{3}{c}{ TP Pollution } & \multicolumn{2}{c}{ TN and TP Pollution } \\
\cline { 2 - 9 } & $\begin{array}{c}\text { Light } \\
\text { DFAA }\end{array}$ & $\begin{array}{c}\text { Moderate } \\
\text { DFAA }\end{array}$ & $\begin{array}{l}\text { Severe } \\
\text { DFAA }\end{array}$ & $\begin{array}{c}\text { Light } \\
\text { DFAA }\end{array}$ & $\begin{array}{c}\text { Moderate } \\
\text { DFAA }\end{array}$ & $\begin{array}{c}\text { Severe } \\
\text { DFAA }\end{array}$ & $\begin{array}{c}\text { Light } \\
\text { DFAA }\end{array}$ & $\begin{array}{c}\text { Moderate } \\
\text { DFAA }\end{array}$ & $\begin{array}{c}\text { Severe } \\
\text { DFAA }\end{array}$ \\
\hline RCP2.6 & $97.14 \%$ & $100.00 \%$ & $100.00 \%$ & $14.29 \%$ & $0.00 \%$ & $0.00 \%$ & $14.29 \%$ & $0.00 \%$ & $0.00 \%$ \\
RCP4.5 & $96.30 \%$ & $100.00 \%$ & $100.00 \%$ & $14.81 \%$ & $0.00 \%$ & $0.00 \%$ & $14.81 \%$ & $0.00 \%$ & $0.00 \%$ \\
RCP8.5 & $92.86 \%$ & $100.00 \%$ & $100.00 \%$ & $0.00 \%$ & $16.67 \%$ & $66.67 \%$ & $0.00 \%$ & $16.67 \%$ & $66.67 \%$ \\
\hline
\end{tabular}

\section{Discussion}

\subsection{Evolution of DFAA}

According to the prediction results of RCPs, the annual precipitation presented an increasing trend in the LRB, from 2020 to 2050, with significant alternation of wet and dry [41]. Also, the basin experiences semi-arid, semi-humid and humid temperate continental monsoon climate from northwest to southeast. More than two-thirds of the annual precipitation was concentrated in summer. The analysis results of the evolution characteristics show that the frequency of DFAA increased from northwest to southeast, both in each season and in whole year. And most of the DFAA events were concentrated in summer and located in the lower reaches of the LRB. As the downstream of the LRB is in a plain area, it can be seen that DFAA events occur more easily in the plain area. At the same time, downstream of the LRB is the irrigation area where the non-point source pollution can be brought out more easily. The precipitation amount was small in spring and increased largely in the summer, easily causing the DFAA during this time. As the humidity increases from northwest to southeast, the occurrence probability of abnormal precipitation increases from northwest to southeast as well. The evolution of DFAA is in accordance with the prediction of RCPs and the precipitation distribution in the LRB.

For the DFAA in different levels, the DFAA events decreased according to the following order: Light DFAA > moderate DFAA > severe DFAA, indicating that the light drought-light flood, light drought-moderate flood, and moderate drought-light flood occurred more frequently. In addition, the DFAA events occurred more concentrated in the south and east of the LRB, which is similar to the DFAA in different seasons. The prediction results of RCPs showed that in RCP2.6 and RCP4.5, the precipitation had a significant increase in the downstream plain area; in RCP8.5, large precipitation increases were located in the upper and middle reaches. That is the reason that, in RCP2.6 and RCP4.5, the DFAA events occurred more in the downstream; while in RCP8.5, the DFAA events also occurred frequently in the upper and middle reaches.

\subsection{Impacts of DFAA on Surface Water Quality}

The prediction results of RCPs reveal that the precipitation and temperature will increase from 2020 to 2050, compared with the historical period (from 1963 to 2017) [42]. The increase in temperature and extreme precipitation will aggravate water pollution, which directly or indirectly affect the water quality in the basin [46,47]. The IPCC report also records these phenomena [48]. The analysis of the incidence of TN and TP pollution indicates that the water pollution possibility increased when DFAA occurred, and TN pollution is more serious than TP pollution from 2020 to 2050 in the LRB. This can be explained by the following: Precipitation change will affect the occurrence of droughts and floods. A sudden precipitation increase will aggravate atmospheric deposition and surface erosion, also sudden heavy precipitation will increase the scouring effect as surface runoff becomes more evident. This will cause many surface pollutants, especially the non-point source pollutants to enter water bodies [49], then exerting a subtle influence on the water quality. Nitrogen and phosphorus are the two main elements of non-point source pollution [50]. Meanwhile, flood disasters will also increase the sediment amount in the water bodies, affecting the pollutants transport, further influencing water quality [51]. Also, the temperature increase in the future will affect the chemical reaction rate and microbial degradation 
ability of aquatic organisms [52]. Simulation experiments show that nitrogen and phosphorus are released easily from sediment to bottom water with temperature increase, and lead to an increase in nitrogen and phosphorus concentrations in surface water. The incidence of TP pollution is also much less than TN pollution in the history, which indicates that the variation trend of the incidence of TN and TP pollution in the future is in accordance with that in the history in the LRB.

\section{Conclusions}

The evolution of DFAA and its impacts on surface water quality in the LRB, from 2020 to 2050, were investigated under RCPs simulations. The major conclusions are as follows:

(1) Under RCP2.6, RCP4.5, and RCP8.5, the DFAA occurred more frequently in summer (from June to August) than in autumn or spring, and there were no DFAA events in winter. The frequency of DFAA increased from northwest to southeast in each season and in whole year. The DFAA events were concentrated in the downstream of the LRB, in plain and irrigation areas.

(2) For different DFAA levels, the DFAA in three RCPs decreased according to the following order: Light DFAA > moderate DFAA > severe DFAA. Most of the DFAA events were in light level. Meanwhile, the DFAA events occurred more frequently in the downstream of the LRB in all three RCPs, while some DFAA occurred in the upper and middle streams of the LRB under RCP8.5.

(3) The incidence of TN and TP pollution was applied to evaluate the impact of DFAA on surface water quality. The incidence of TN pollution was much larger than the incidence of TP pollution, and simultaneous occurrence of TN and TP pollution. When DFAA occurred, TN pollution almost occurred simultaneously. Meanwhile, when TP pollution occurred, the TN pollution occurred simultaneously. The incidence of TN pollution, TP pollution, simultaneous occurrence of TN and TP pollution showed similar variation laws in all RCPs, increasing according to the following order: Normal months < total months < DFAA months. For different DFAA levels, the incidence of TN pollution in all RCPs increased as: Light DFAA $<$ moderate DFAA = severe DFAA.

In general, the DFAA occurred more frequently, from 2020 to 2050, in the downstream, located in the southeast of the LRB. Future climate change, such as increases in temperature and extreme precipitation, will exacerbate water pollution, further augmenting the risk of extreme water quality events in future DFAA. The evolution characteristics of DFAA in this study can provide references for future climate change study, and also can support the extreme weather effects and adaptation-strategy study, thus guiding drought resistance, flood control, and pollution control in the LRB. Further studies can focus on the transport and transformation mechanism of nitrogen and phosphorus in different forms, both theoretical analysis and practical application are needed.

Author Contributions: W.B. drafted the manuscript. B.W. designed the project and provided overall guidance. W.B. and Z.Y. provided the simulation method. W.B., B.W., and Y.Y. finalized the manuscript. T.X., D.Y., and J.M. collected the data. All authors reviewed the manuscript.

Funding: This work was supported by the National Key Research and Development Project (No. 2016YFA 0601503), the National Science Fund for Distinguished Young Scholars (No. 51725905), the National Key Research and Development Project (No. 2017YFA0605004), the Research Fund of the State Key Laboratory of Simulation and Regulation of Water Cycle in River Basin (No. SKL2018TS02), and the Public Service Special Project of the Environmental Protection Ministry of China (No. 201509027).

Conflicts of Interest: The authors declare no conflict of interest.

\section{References}

1. Wu, Z.W.; He, J.H.; Li, J.P.; Jiang, Z.H. The summer drought-flood coexistence in the middle and lower reaches of the Yangtze River and analysis of its air-sea background feathers in anomalous years. Chin. J. Atmos. Sci. 2006, 30, 570-577.

2. Frich, P.; Alexander, L.; Dellamarta, P.; Gleason, B.; Haylock, M.; Klein Tank, A.; Peterson, T. Observed coherent changes in climatic extremes during the second half of the twentieth century. Clim. Res. 2002, 19, 193-212. [CrossRef] 
3. Zhai, P.M.; Zhang, X.B.; Wan, H.; Pan, X. Trends in total precipitation and frequency of daily precipitation extremes over China. J. Clim. 2005, 18, 1096-1108. [CrossRef]

4. Xu, M.; Ding, X.J.; Luo, L.S.; Chen, Z.; Xu, S. A possible cause of the low frequency circulation of summer-time drought-flood abrupt alternation over the Huaihe River Basin. Acta Meteorol. Sin. 2013, 71, 86-95.

5. Shi, X.H.; Guo, W.D.; Li, W.Z.; Dai, S.; Lv, H. The sudden turn of drought and flood in spring in northern Qinghai Province, 2013: Characteristics and cause of formation. J. Glaciol. Geocryol. 2015, 37, 376-386.

6. Cheng, Z.; Ding, X.J.; Xu, M.; Luo, L.S. Climate characters of typical droughts-floods abrupt alternation events in the middle-lower reaches of the Yangtze River. Resour. Environ. Yangtze Basin 2012, 21, 115-120.

7. Hastenrath, S.; Polzin, D.; Mutai, C. Diagnosing the droughts and floods in equatorial East Africa during boreal autumn 2005-08. J. Clim. 2010, 23, 813-817. [CrossRef]

8. Wu, Z.; Li, J.; He, J.; Jiang, Z.H. Large-scale atmospheric singularities and summer long-cycle droughts-floods abrupt alternation in the middle and lower reaches of the Yangtze River. Chin. Sci. Bull. 2006, 51, 2027-2034. [CrossRef]

9. Feng, G.L.; Yang, H.W.; Zhang, S.X.; Wang, K.; Shen, B.Z. A preliminary research on the reason of a sharp turn from drought to flood in the middle and lower reaches of the Yangtze River in late spring and early summer of 2011. Chin. J. Atmos. Sci. 2012, 36, 1009-1026.

10. Yang, S.Y.; Wu, B.Y.; Zhang, R.H.; Zhou, S.W. Relationship between an abrupt drought-flood transition over mid-low reaches of the Yangtze River in 2011 and the intraseasonal oscillation over mid-high latitudes of East Asia. Acta Meteorol. Sinica 2013, 27, 129-143. [CrossRef]

11. Shen, B.Z.; Zhang, S.X.; Yang, H.W.; Wang, K.; Feng, G.L. Analysis of characteristics of a sharp turn from drought to flood in the middle and lower reaches of the Yangtze River in spring and summer in 2011. Acta Phys. Sin. 2012, 61, 530-540.

12. Li, M.; Zhu, C.W.; Pang, Y.S. Possible causes of abrupt turning from drought to flooding in the middle and lower reaches of Yangtze River valley during spring to summer of 2011. J. Meteorol. Environ. 2014, 30, 70-78.

13. Ma, P.H.; Yang, Y.J.; Liu, T.J. Cause analysis for the sharp turn from drought to flood in the middle and lower reaches of the Yangtze River during 2011. Meteorol. Disaster Reduct. Res. 2014, 37, 1-6.

14. Li, X.; Ye, X. Spatiotemporal characteristics of dry-wet abrupt transition based on precipitation in Poyang Lake basin, China. Water 2015, 7, 1943-1958. [CrossRef]

15. Zhang, S.F.; Zhang, J.C.; Min, J.J.; Zhang, Z.X.; Zhuang, J.Y.; Lin, J. Drought-flood abrupt alternation based on runoff in the Huaihe River Basin during rainy season. J. Lake Sci. 2012, 24, 679-686.

16. Wang, J.; Duan, L.Y.; He, Q.Y.; Wu, Z.L.; Chen, H.; Zhang, N. Drought-flood abrupt alternation events of Haihe River Basin in main rainy season and their relationships with the anomalous atmospheric circulation. J. Trop. Meteorol. 2016, 32, 1-9.

17. Yan, D.H.; Wu, D.; Huang, R.; Wang, L.N.; Yang, G.Y. Drought evolution characteristics and precipitation intensity changes during alternating dry-wet changes in the Huang-Huai-Hai River basin. Hydrol. Earth Syst. Sci. 2013, 17, 2859. [CrossRef]

18. Zhou, X.; Li, L.; Shan, S.H.; Liu, D.W.; Zhou, H.; Liu, Y. Effect of abrupt droughts-floods on physiology and biochemistry of different peanut varieties. Chin. J. Oil Crop Sci. 2012, 34, 56-61.

19. Deng, Y. The effect of drought-flood abrupt alternation on yield formation and its physiological traits in double-season super hybrid rice. Ph.D. Thesis, Jiangxi Agricultural University, Nanchang, China, 2015.

20. Hu, L.M.; Shi, X.F.; Wang, G.Q.; Qiao, S.Q.; Yang, G.; Gao, J.J.; Bai, Y.Z. Study on the geochemical characteristics of the surface sediments from the Yangtze River estuary under the 2011 sharp turn from drought to flood in middle and lower Yangtze. Geochimica 2014, 43, 39-54.

21. Tian, R.; Cao, C.X.; Peng, L.; Ma, G.R.; Bao, D.M.; Guo, J.H.; Yomwan, P. The use of HJ-1A/B satellite data to detect changes in the size of wetlands in response in to a sudden turn from drought to flood in the middle and lower reaches of the Yangtze River system in China. Geomat. Nat. Hazards Risk 2016, 7, 287-307. [CrossRef]

22. Barros, M.C.; Mendo, M.J.M.; Negrão, F.C.R. Surface water quality in Portugal during a drought period. Sci. Total Environ. 1995, 171, 69-76. [CrossRef]

23. Mimikou, M.A.; Baltas, E.; Varanou, E.; Pantazis, K. Regional impacts of climate change on water resources quantity and quality indicators. J. Hydrol. 2000, 234, 95-109. [CrossRef]

24. Murdoch, P.S.; Baron, J.S.; Miller, T.L. Potential effects of climate change on surface-water quality in North America. JAWRA 2000, 36, 347-366. 
25. Caruso, B.S. Temporal and spatial patterns of extreme low flows and effects on stream ecosystems in Otago, New Zealand. J. Hydrol. 2002, 257, 115-133. [CrossRef]

26. Zhu, Z.; Arp, P.A.; Mazumder, A.; Meng, F.R.; Bourque, C.P.A.; Foster, N.W. Modeling stream water nutrient concentrations and loadings in response to weather condition and forest harvesting. Ecol. Model. 2005, 185, 231-243. [CrossRef]

27. Chen, B.F. Study on the impacts of drought on water environment in Majia River Basin. Ph.D. Thesis, Ocean University of China, Qingdao, China, 2013.

28. Chouyyok, W.; Wiacek, R.J.; Pattamakomsan, K.; Sangvanich, T.; Grudzien, R.M.; Fryxell, G.E. Phosphate removal by anion binding on functionalized nanoporous sorbents. Environ. Sci. Technol. 2010, 44, 3073-3078. [CrossRef] [PubMed]

29. Niu, J.L.; He, Z.Y.; Zhang, T.Y.; Chen, X.Y. Impacts of sudden drought to flood change on manufacture livelihood and ecology. Resour. Environ. Yangtze Basin 2013, s1, 108-115.

30. Xiao, M.; Yu, S.; Wang, Y.Y.; Huang, R. Nitrogen and phosphorus changes and optimal drainage time of flooded paddy field based on environmental factors. Water Sci. Eng. 2013, 6, 164-177.

31. Minister of Environmental Protection of the People's Republic of China. Available online: http://www.zhb. gov.cn/gkml/hbb/qt/201706/t20170605_415442.htm (accessed on 16 December 2018).

32. Zhu, X.C.; Wang, L.M.; Liu, J.X. Analysis and measures to water resources utilization in Luanhe River Basin. Haihe Water Resour. 2015, 1, 6-8.

33. Hou, X.L.; Huang, Y. Characteristics and influential factors analysis on the quality of Luan River water and groundwater. Environ. Prot. Circ. Econ. 2017, 03, 41-45.

34. Shi, X.L.; Yang, Z.Y.; Yan, D.H.; Li, Y.; Yuan, Z. On hydrological response to land-use/cover change in Luanhe River Basin. Adv. Water Sci. 2014, 25, 21-27.

35. Li, Y.; Huang, S.L. Hydrological responses to land use change under three future scenarios in Luanhe River Basin. Chin. J. Ecol. 2016, 7, 1970-1980.

36. Yuan, Z. Drought Risk Assessment and Its Coping Strategies under Changing Environments: A Case Study in Luanhe River Basin. Ph.D. Thesis, China Institute of Water Resources and Hydropower Research, Beijing, China, 2016.

37. Yuan, Z.; Yang, Z.Y.; Yan, D.H.; Yin, J. Historical changes and future projection of extreme precipitation in China. Theor. Appl. Climatol. 2017, 127, 393-407. [CrossRef]

38. Williams, J.; Nearing, M.; Nicks, A.; Skidmore, E.; Valentin, C.; King, K.; Savabi, R. Using soil erosion models for global change studies. J. Soil Water Conserv. 1996, 51, 381-385.

39. Cai, Y.M.; Zhang, K.L.; Li, S.C. Study on the conversion of different soils texture. Acta Pedol. Sin. 2003, 40, 511-517.

40. Tong, C.L.; Zhang, W.J.; Tang, Y.; Wang, H.Q. Estimation of Daily Solar Radiation in China. Chin. J. Agrometeorol. 2005, 26, 165-169.

41. Yuan, Z.; Yan, D.H.; Yang, Z.Y.; Yin, J. Ensemble model and its application in runoff simulation and forecast. J. Hydraul. Eng. 2014, 3, 351-359.

42. Bi, W.X.; Weng, B.S.; Yuan, Z.; Ye, M.; Zhang, C.; Zhao, Y.; Yan, D.M.; Xu, T. Evolution Characteristics of Surface Water Quality Due to Climate Change and LUCC under Scenario Simulations: A Case Study in the Luanhe River Basin. Int. J. Env. Res. Public Health 2018, 15, 1724. [CrossRef] [PubMed]

43. State Environmental Protection Administration, General Administration of Quality Supervision, Inspection and Quarantine of China (2002). Environmental Quality Standards for Surface Water (GB3838-2002). Available online: http:/ / datacenter.mep.gov.cn/websjzx/dataproduct/resourceQuery/querymeta.vm? dataId=66497 (accessed on 16 December 2018).

44. The Ministry of Water Resources of the People's Republic of China. Standard of Classification for Drought Severity (SL424-2008); China Water \& Power Press: Beijing, China, 2008.

45. Liu, S.H. The rainfall infiltration coefficient research based on high frequency water level dynamic monitoring in the north China plain. Ph.D. Thesis, China University of Geosciences, Wuhan, China, 2013.

46. Kaste, Ã.; Wright, R.F.; Barkved, L.J.; Bjerkeng, B.; Engen-Skaugen, T.; Magnusson, J.; Saelthun, N.R. Linked models to assess the impacts of climate change on nitrogen in a Norwegian river basin and fjord system. Sci. Total Environ. 2006, 365, 200-222. [CrossRef] [PubMed]

47. Ducharne, A. Importance of stream temperature to climate change impact on water quality. Hydrol. Earth Syst. Sci. 2008, 4, 797-810. [CrossRef] 
48. Stocker, T. IPCC, 2013: Technical Summary. In: Climate Change 2013: The Physical Science Basis. Contribution of Working Group I to the Fifth Assessment Report of the Intergovernmental Panel on Climate Change. Comput. Geom. 2013, 18, 95-123.

49. Curriero, F.; Patz, J.; Rose, J.; Lele, S. Analysis of the association between extreme precipitation and waterborne disease outbreaks in the United States, 1948-1994. Epidemiology 2001, 12, S37.

50. Panda, R.K.; Behera, S. Non-point source pollution of water resources: Problems and perspectives. J. Food Agric. Environ. 2003, 1, 308-311.

51. Hilscherova, K.; Dusek, L.; Kubik, V.; Cupr, P.; Hofman, J.; Klanova, J.; Holoubek, I. Redistribution of organic pollutants in river sediments and alluvial soils related to major floods. J. Soils Sediments 2007, 7, 167-177. [CrossRef]

52. Xia, X.H.; Wu, Q.; Mou, X.L. Advances in impacts of climate change on surface water quality. Adv. Water Sci. 2012, 23, 124-133.

(C) 2019 by the authors. Licensee MDPI, Basel, Switzerland. This article is an open access article distributed under the terms and conditions of the Creative Commons Attribution (CC BY) license (http:/ / creativecommons.org/licenses/by/4.0/). 